\title{
Wash resistance and repellent properties of Africa University mosquito blankets against mosquitoes
}

\author{
N. Lukwa, ${ }^{1}$ A. Makuwaza, ${ }^{1}$ T. Chiwade, ${ }^{1}$ S.L. Mutambu, ${ }^{1}$ M. Zimba, ${ }^{2}$ P. Munosiyei ${ }^{3}$ \\ ${ }^{1}$ National Institute of Health Research, Causeway, Harare; ${ }^{2}$ University of Zimbabwe, Biological \\ Sciences, Mount Pleasant, Harare; ${ }^{3}$ Bindura University of Science Education, Bindura, Zimbabwe
}

\begin{abstract}
The effect of permethrin-treated Africa University (AU) mosquito blankets on susceptible female Anopheles gambiae sensu lato mosquitoes was studied under laboratory conditions at Africa University Campus in Mutare, Zimbabwe. Wash resistance (ability to retain an effective dose that kills $\geq 80 \%$ of mosquitoes after a number of washes) and repellence (ability to prevent $\geq 80 \%$ of mosquito bites) properties were studied. The AU blankets were wash resistant when $100 \%$ mortality was recorded up to 20 washes, declining to $90 \%$ after 25 washes. Untreated AU blankets did not cause any mortality on mosquitoes. However, mosquito repellence was $96 \%, 94 \%, 97.9 \%, 87 \%, 85 \%$ and $80.7 \%$ for treated AU blankets washed $0,5,10,15,20$ and 25 times, respectively. Mosquito repellence was consistently above $80 \%$ from $0-25$ washes. In conclusion, AU blankets washed 25 times were effective in repelling and killing An. gambiae sl mosquitoes under laboratory conditions.
\end{abstract}

Correspondence: Nzira Lukwa, National Institute of Health Research, P.O. Box CY573, Causeway, Harare, Zimbabwe. Tel.: +263.4.797052; +263.274664 Fax: +263.4.253979. E-mail: nziraa33@yahoo.co.uk

Key words: An. gambiae sl, wash resistance, repellence, bioassays, permethrin.

Acknowledgements: the authors would like to acknowledge the support provided by Mr Chinyanya and Ms Gidi. Permission to carry out the research was granted by the then Provincial Medical Director for Manicaland province (Dr Banda). All participants are fully acknowledged. Funding was provided by Africa University. Ethical approval for this study was granted by the Medical Research Council of Zimbabwe.

Received for publication: 28 August 2012.

Revision received: 9 January 2013.

Accepted for publication: 1 February 2013

(C) Copyright N. Lukwa et al., 2013

Licensee PAGEPress, Italy

Journal of Entomological and Acarological Research 2013; 45:e5

doi:10.4081/jear.2013.e5

This article is distributed under the terms of the Creative Commons Attribution Noncommercial License (by-nc 3.0) which permits any noncommercial use, distribution, and reproduction in any medium, provided the original author(s) and source are credited.

\section{Introduction}

Malaria is one of the killer diseases affecting Zimbabwe, mostly in the low veldt due to the conducive environment prevailing in these areas. The Ministry of Health and Child Welfare (MoHCW) has a mandate to control malaria through the National Malaria Control Program (NMCP) that has defined structures from head office, provincial, down to district levels. The NMCP co-ordinates all malaria control activities in the country using the integrated vector management approach that includes indoor residual spraying, insecticide treated materials (ITMs), larviciding and use of personal protection methods (Lukwa, 1994; Taylor \& Mutambu, 1986).

Personal protection is one of the malaria control methods advocated for at community level. ITMs have been used for some time although the use of treated blankets is relatively uncommon. Long-lasting permethrin-treated nets used as blankets inhibited $35-60 \%$ of mosquitoes from entering the huts and eventually $88-98 \%$ of them died (Hougard et al., 2007). The use of treated-blankets and sheets reduced malaria infection in the intervention group by $70 \%$ (Kimani et al., 2006). In another study, insecticide-treated bedding protected people against malaria and leishmaniasis vectors, since the mean mortality rates were 16-30.3\% (Graham et al., 2002).

The results on acceptability clearly showed that providing treated bedding resulted in protection from mosquito bites (Graham et al., 2002). Chaddars (head dress) treated with permethrin were evaluated in several villages in Afghanistan with a 7.2\% incidence rate of leishmaniasis for the control group and 2.5\% for people using permethrintreated chaddars (Reyburn et al., 2000). Up to 8\% of the respondents using treated chaddars for the control of leishmaniasis were convinced that chaddars prevent bites from sand flies, as compared to $28 \%$ who did not feel any change in sand fly biting (control group) (Reyburn et al., 2000). Permethrin-treated chaddars killed $36-70 \%$ of the mosquitoes exposed to the treatment as compared to $20-39 \%$ of the mosquitoes that were killed in the controls (Rowland et al., 1999). The World Health Organization (WHO) (WHO, 2006) set the criteria for 24-h mortality at $80 \%$ or over.

Although the use of long-lasting insecticide-treated mosquito nets (LLINs) is an important part of malaria control in Zimbabwe, treated blankets have never been used for this purpose. Studies were carried out at Africa University, Mutare, on the possibility of using Africa University (AU) mosquito blanket for controling mosquitoes.

\section{Materials and methods}

\section{Study area}

Mosquitoes were collected from selected breeding sites from 
Chakohwa village $\left(19^{\circ} 51^{\prime} \mathrm{S}, 32^{\circ} 55^{\prime} \mathrm{E}\right)$ where malaria transmission is moderate. The inhabitants are mostly subsistence farmers who specialize in growing maize. Some irrigation is practised for vegetables. Laboratory tests were carried out using facilities at Africa University ( $18^{\circ} 52^{\prime}$ S, $32^{\circ} 42^{\prime}$ E) located near Mutare City, Zimbabwe.

\section{Mosquito collection and rearing}

The Anopheles gambiae sensu lato mosquito larvae were collected from the fringes of rivers (Figure 1) using soup ladles in breeding sites in Chakohwa village. The larvae were placed in rearing bowls (Figure 2) and later covered using mosquito netting. All the larvae were fed on fish food until they pupated. The pupa were picked up using a $2 \mathrm{~mL}$ plastic pipette, placed in a small dish before being placed in $5 \mathrm{~L}$ plastic mosquito cages to hatch. The upper part of the mosquito cage is open and has netting, and a sleeve is provided for introducing and retrieving mosquitoes. The adults were fed on $10 \%$ sugar solution that had been daubed in cotton wool and placed on top of the cage. The adult An. gambiae sl mosquitoes from this study area have not been identified to species level.

A sample of the resultant adults was used to determine levels of insecticide susceptibility and the rest were used for bioassays. The adult mosquitoes were susceptible to the 4 classes of insecticides, namely pyrethroids (lambda-cyhalothrin), organophosphates (malathion), organochlorines (dichloro-diphenyl-trichloroethane) and cabarmates (bendiocarb).

\section{Repellent blanket}

The AU mosquito blanket (also known as the Chicopee Insect Shield) measures $187.96 \times 121.92 \mathrm{~cm}$ and weighs $567 \mathrm{~g}$. It is manufactured by BuzzOff ${ }^{\mathrm{TM}}$ (S.C. Johnson \& Son, Inc., St Racine, WI, USA) and is treated with $0.52 \%$ permethrin at the factory. The blanket can be used as a wrapper or top sheet (i.e. placed on top of blankets). The control blanket was made by the same manufacturer but it did not contain insecticide.

\section{World Health Organization's washing procedure}

The blanket was cut into $25 \times 25 \mathrm{~cm}$ pieces, with 6 pieces for each wash $(0,5,10,15,20$ and 25$)$. Each piece was individually introduced into a $1 \mathrm{~L}$ beaker containing $500 \mathrm{~mL}$ of distilled water (with $1 \mathrm{~mL} / \mathrm{L}$ soap) added. The beakers were introduced into a water bath that contained water at a temperature of $30^{\circ} \mathrm{C}$. The water bath was set at 155 movements per min for $10 \mathrm{~min}$. After $10 \mathrm{~min}$, the beakers were removed from the water bath and the pieces of blankets removed. Each piece of blanket was rinsed twice for $10 \mathrm{~min}$ in clean distilled water in the same shaking conditions and dried under cover. All pieces of blanket were kept uncontaminated before use. Bioassays (described under wash resistance properties) were only performed on dry blanket samples (WHO, 2005).

\section{Wash resistance properties}

Wash resistance properties were evaluated on either permethrintreated or untreated samples of AU blankets that were washed using the standard WHO washing procedure (WHO, 2005). Each WHO cone measured $8.5 \mathrm{~cm}$ in diameter at the base and was $5.5 \mathrm{~cm}$ high. Each piece of was fastened to the WHO cone using a rubber band (6 replicates for each wash) (Figure 3 ). A total of 5 non-blood fed (2-5 days old) An. gambiae s.l adult female mosquitoes were aspirated using a sucking tube (carried out through the small hole in the cone) and exposed to each blanket sample for $30 \mathrm{~min}$. Mosquitoes from each WHO cone were retrieved and placed in holding paper cups after being provided with $10 \%$ sugar solution in the form of a cotton swab used as a wick. Mortality was recorded $24 \mathrm{~h}$ after exposure. This procedure was repeated for all the 6 washes $(0,5,10,15,20$ and 25$)$.

\section{Repellence test}

Mosquito cages were made from $5 \mathrm{~L}$ buckets consisting of a sleeve for introducing mosquitoes and covered with mosquito netting on top and used for each test. Five cages per wash were prepared simultaneously for each of the 6 washes. Fifty starved laboratory-reared female An. gambiae s.l were placed in each mosquito cage and left to acclimatize for $1 \mathrm{~h}$ in studies that were replicated 5 times. Each piece of blanket was wrapped around each hand (Figure 4) and placed in the mosquito cage (Figure 5). One hand was placed in the cage containing mosquitoes for 2 min and the number of mosquitoes probing to bite recorded as described by Maharaj et al. (2010). This was carried out for untreated and treated pieces of blanket. Repellence tests were performed following the test method previously described by Curtis et al. (1990). Percentage mosquito repellence was calculated following the method previously described by Mehr et al. (1985) as follows:

$$
\left(\bar{B}_{c}-\bar{B}_{t} / \bar{B}_{c}\right) * 100
$$

where

$\mathrm{B}_{\mathrm{c}}$ is the mean number of bites on control; and

$B_{t}$ is the mean number of bites on treated pieces of blanket.

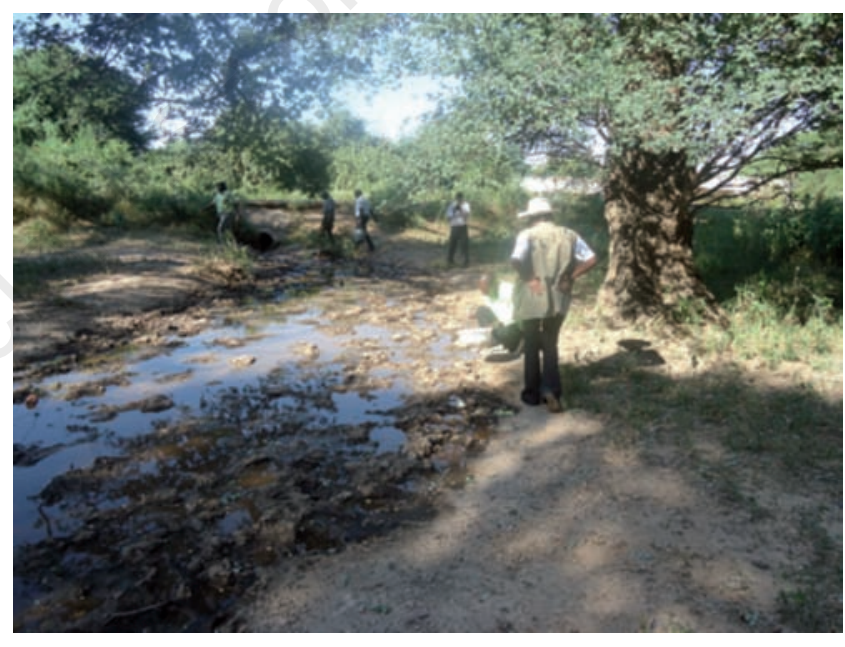

Figure 1. Fringes of mosquito breeding site.

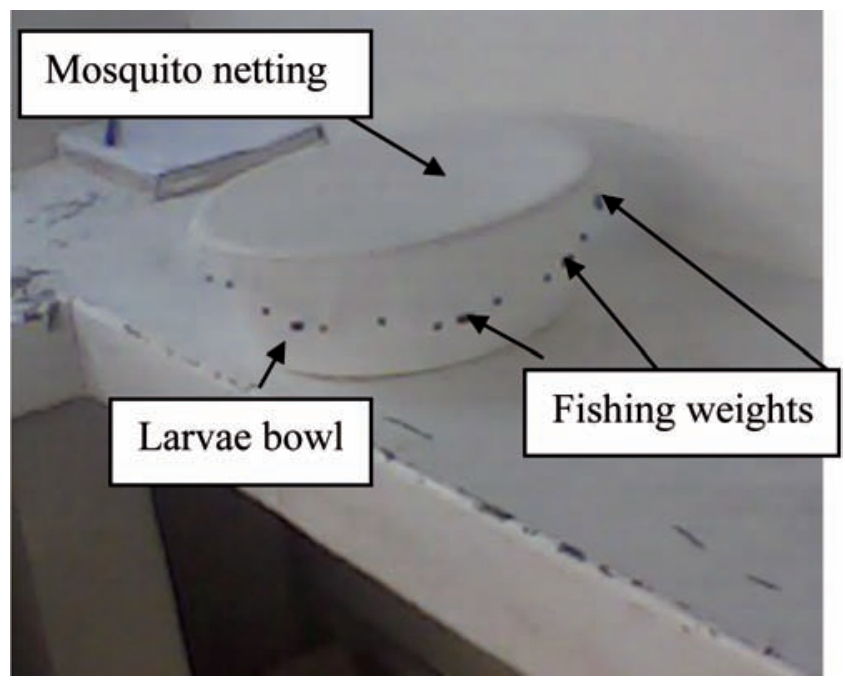

Figure 2. Mosquito rearing bowl with mosquito netting. 
The cut-off point for repellence was $80 \%$ or over as described by Maharaj et al. (2010).

\section{Data analysis}

An analysis of variance (ANOVA) test of variance using the 95\% confidence limit was carried out to test statistical difference.

\section{Results}

AU treated mosquito blankets were wash resistant for up to 25 washes since the mortality was above $80 \%$, as stipulated by the WHO (2005) (Table 1). One hundred percent mortality was realized up to 20 washes before it decreased at 25 washes when treated blankets were used. No mortality occurred with the untreated blankets.

In mosquito repellent studies, more mosquitoes were biting the persons using untreated samples of the blanket than the treated, and the results were significantly different for all washes $(\mathrm{P}<0.0001)$ (Table 2$)$. Mosquito repellent properties of treated AU blankets were observed for up to 25 washes since repellence was above $80 \%$ as reported by Maharaj et al. (2010).
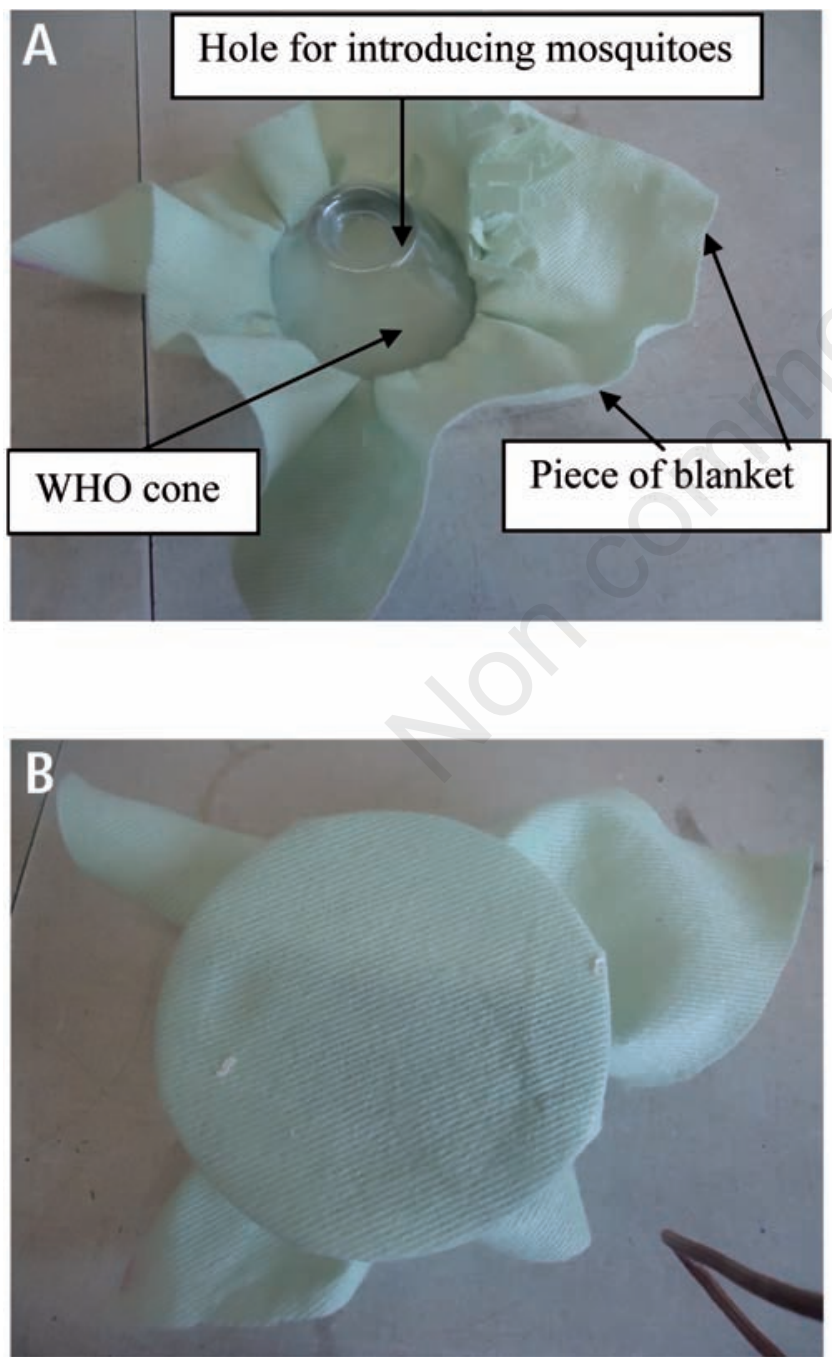

Figure 3. A) Bottom of World Health Organization's (WHO) cone; B) top of WHO cone covered with piece of blanket.

\section{Discussion and conclusions}

Studies on wash resistance properties showed that the treated AU blanket killed mosquitoes for up to 25 washes, in agreement with Rowland et al. (1999). Thus, enough lethal insecticide was retained on treated pieces of blanket for up to 25 washes. When blankets are not

Table 1. Wash resistance properties of Africa University treated mosquito blankets three days after washing.

\begin{tabular}{ll} 
No. of washes & Mortality (\%) \\
0 & $30 / 30(100)$ \\
5 & $30 / 30(100)$ \\
\hline 10 & $28 / 28(100)$ \\
15 & $31 / 31(100)$ \\
\hline 20 & $27 / 27(100)$ \\
25 & $27 / 30(90)$ \\
\hline
\end{tabular}

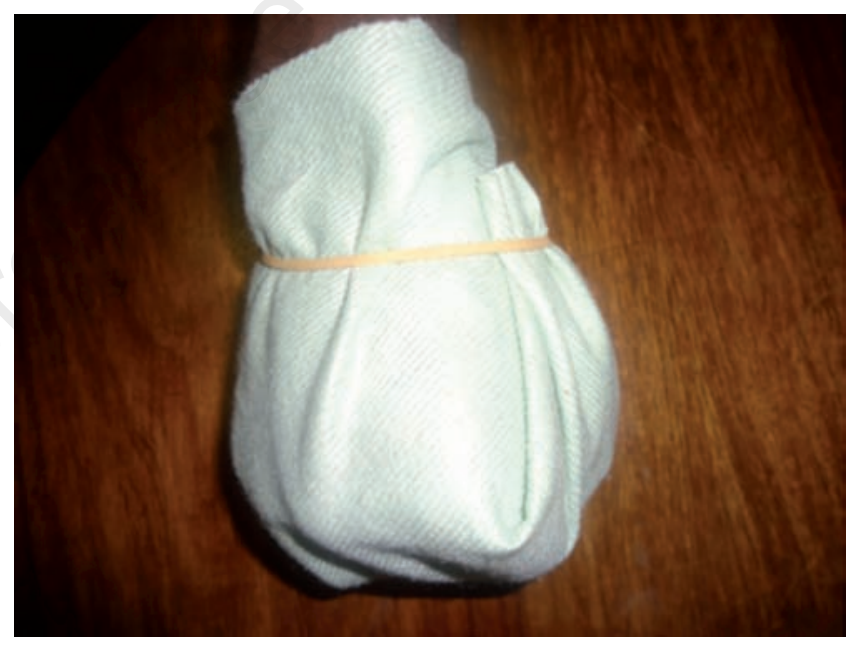

Figure 4. Hand wrapped in piece of blanket during repellence test.

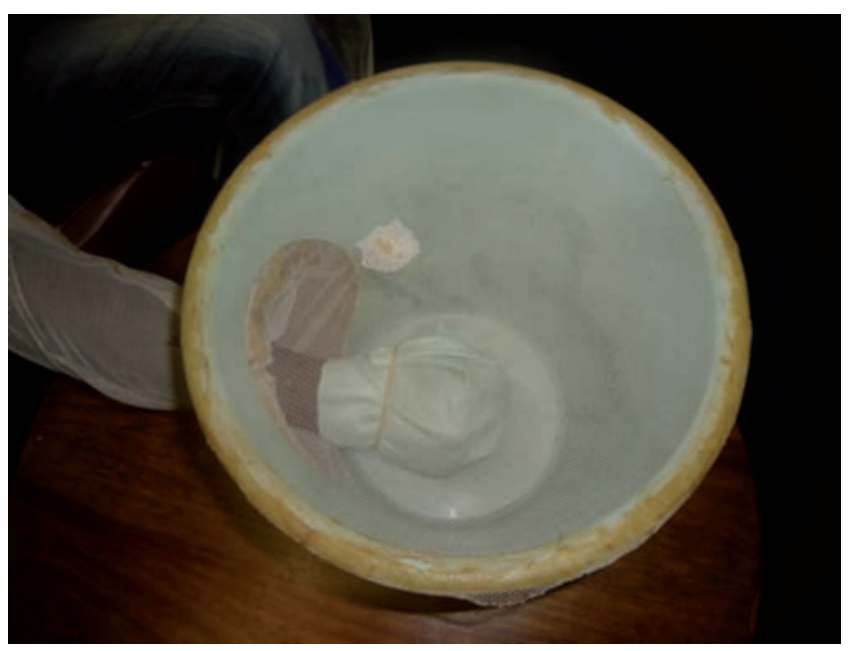

Figure 5. Hand introduced into mosquito cage for repellence test. 
Table 2. Number of mosquitoes probing to bite people using treated and untreated blanket samples and their repellence effect.

\begin{tabular}{|c|c|c|c|}
\hline No. of washes & $\begin{array}{l}\text { Treate } \\
\text { No. of mosquitoes probing to bite } \\
\text { Total (range) }\end{array}$ & $\begin{array}{l}\text { AU blankets } \\
\text { Repellence [control-treated/control] }{ }^{*} 100\end{array}$ & $\begin{array}{c}\text { Untreated AU blankets } \\
\text { No. of mosquitoes probing to bite } \\
\text { Total (range) }\end{array}$ \\
\hline 0 & $5(0-2)$ & 96.0 & $125(18-37)$ \\
\hline 5 & $7(1-2)$ & 94.0 & $118(17-30)$ \\
\hline 10 & $3(0-1)$ & 97.9 & $145(26-33)$ \\
\hline 15 & $16(3-4)$ & 87.0 & $123(23-26)$ \\
\hline 20 & $18(2-5)$ & 85.0 & $120(23-26)$ \\
\hline 25 & $26(4-7)$ & 80.7 & $135(24-30)$ \\
\hline
\end{tabular}

properly treated during manufacture, insecticide can be lost quickly during washing, thus losing the protective efficiency. When this happens, mosquitoes will no longer be killed and people living in malarious areas will be exposed to infective mosquito bites. The more wash resistant the treated blankets are, the longer they last in protecting vulnerable populations. The quality of the fiber used in blanket manufacture has a bearing on how long the treated blankets will last.

Observations of Graham et al. (2002) on mortality (16-30\%) of mosquitoes were not as good as ours (90-100\%), implying that AU treated blankets worked better than treated bedding. However, our results on mortality were slightly better than (LLINs) treated with permethrin but used as top sheets (88-98\%) (Hougard et al., 2007).

On the other hand, treated AU blankets have proved to be good repellents for up to 25 washes and our results were better than those of Hougard et al. (2007). The treated AU blankets minimize the number of mosquitoes that land and, therefore, reduce malaria transmission. Results from this study show that treated blankets might offer protection from mosquito bites even if they have been washed 25 times. These results point to the use of a new concept (repellent blankets) in malaria control.

\section{References}

CURTIS C.F., LINES J.D., BAOLIN L., RENZ A., 1990 - Natural and synthetic repellents. In: CURTIS C.F., ed., Appropriate technology in vector control. - CRC Press, Boca Raton, FL: 75-92.

GRAHAM K., MOHAMAD N., REHMAN H., FARHAN M., KAMAL M., ROWLAND M., 2002 - Comparison of three pyrethroid treatments of top sheets for malaria control in emergencies: entomological user acceptance studies in an Afghan refugee camp in Pakistan. - Med. Vet. Entomol. 16: 199-206.

HOUGARD J.M., MARTIN T., GUILLET P.F., COOSEMANS M., ITOH T., AKOGBETO M., et al., 2007 - Preliminary field testing of a long-lasting insecticide-treated hammock against Anopheles gambiae and Mansonia spp. (Diptera: Culicidae) in West Africa. - J. Med. Entomol. 44: 651-655.
KIMANI E.W., VULULE J.M., KURIA I.W., MUGISHA F., 2006 - Use of insecticide-treated clothes for personal protection against malaria: a community trial. - Malaria J. 27: 63.

LUKWA N., 1994 - Do traditional repellent plants work as mosquito larvicides?. - Cent. Afr. J. Med. 40: 306-325.

MAHARAJ R., MAHARAJ V., NEWMARCH M., CROUCH N.R., BHAGWANDIN N., FOLB P.I., et al., 2010 - Evaluation of selected South African ethno-medicinal plants as mosquito repellents against the Anopheles arabiensis mosquito in a rodent model. - Malaria J. 9: 301.

MEHR Z.A., RUTLEDGE L.C., MORALES E.L., MEIXSALL V.E., KORTE D.W., 1985 - Laboratory evaluation of controlled release insect repellent formulations. - J. Am. Mosquito Control Assoc. 1: 143-147.

REYBURN H., ASHFORD R., MOHSEN M., HEWITT S., ROWLAND M., 2000 - A randomised controlled trial of insecticide treated bed nets and chaddars or top sheets, and residual spraying of interior rooms for the prevention of cutaneous leishmaniasis in Kabul, Afghanistan. - Trans. R. Soc. Trop. Med. Hyg. 94: 361-366.

ROWLAND M., DURRANI N., HEWITT S., MOHAMMAD N., BOUMA M., CARNEIRO 0., et al., 1999 - Permethrin treated chaddars and top sheets: appropriate technology for protection against malaria in Afghanistan and other complex emergencies. - Trans. R. Soc. Trop. Med. Hyg. 93: 465-472.

TAYLOR P., MUTAMBU S.L., 1986 - A review of the malaria situation in Zimbabwe with special reference to the period 1972-1981. - Trans. R. Soc. Trop. Med. Hyg. 80: 12-19.

WORLD HEALTH ORGANIZATION, 2005 - Guidelines for laboratory and field testing of long-lasting insecticidal mosquito nets; WHO/CDS/WHOPES/GCDPP/2005.11. - World Health Organization, Geneva. Available from: http://whqlibdoc.who.int/hq/2005/WHO CDS_WHOPES_GCDPP_2005.11.pdf

WORLD HEALTH ORGANIZATION, 2006 - Guidelines for testing mosquito adulticides for indoor residual spraying and treatment of mosquito nets; WHO/CDS/WHOPES/GCDPP/2006.3. - World Health Organization, Geneva. Available from: http://whqlibdoc.who.int/hq/ 2006/WHO_CDS_NTD_WHOPES_GCDPP_2006.3_eng.pdf 